\title{
Evaluation of Community-Based Cessation Programs: How Do Smokers with Behavioral Health Conditions Fare?
}

\author{
Clare Meernik ${ }^{1}$ (1) $\cdot$ Anna McCullough ${ }^{1} \cdot$ Leah Ranney $^{1} \cdot$ Barbara Walsh $^{2} \cdot$ \\ Adam O. Goldstein ${ }^{1,3}$
}

Received: 3 May 2016 / Accepted: 30 July 2017 / Published online: 2 August 2017

\begin{abstract}
Though persons with behavioral health conditions experience large disparities in tobacco use, questions about the efficacy of evidence-based tobacco use treatment remain understudied in community health settings. This evaluation examined outcomes from eight communitybased tobacco cessation programs for participants with and without behavioral health conditions ( $\mathrm{n}=974$ participants). The majority (64.8\%) of participants reported one or more current behavioral health conditions, including mental illness and/or substance abuse. Participants who used cessation medication during the program and who attended more counseling sessions had an increased likelihood of being quit at 4-month follow-up. Quit rates were between 9.8\% (intent-to-treat rate) and 30.6\% (responder rate); behavioral health status did not negatively affect reported quit rates. Findings add to the growing literature evaluating community-based interventions within the behavioral health population.
\end{abstract}

Keywords Smoking $\cdot$ Smoking cessation $\cdot$ Mental health $\cdot$ Behavioral counseling $\cdot$ Tobacco use cessation products

Clare Meernik

cmeernik@email.unc.edu

1 Department of Family Medicine, University of North Carolina, 590 Manning Drive, CB 7595, Chapel Hill, NC 27599, USA

2 CT Department of Public Health, 410 Capitol Avenue, MS\#11 HLS, P. O. Box 340308, Hartford, CT 06134, USA

3 Lineberger Comprehensive Cancer Center, University of North Carolina at Chapel Hill, 101 Manning Drive, Chapel Hill, NC 27514, USA

\section{Introduction}

More than half of the roughly 42 million smokers in the United States have made a recent quit attempt, though only $6.2 \%$ stayed quit for at least six months (Centers for Disease Control and Prevention 2011; Jamal et al. 2014). Combined behavioral support and pharmacotherapy can significantly enhance cessation, with 6-month quit rates as high as $25 \%$ in some circumstances (Fiore et al. 2008; Stead and Lancaster 2012). U.S. Clinical and American Psychiatric Association Practice Guidelines recommend these treatment strategies for all tobacco users, including those with mental illness and/or substance use (hereafter referred to as behavioral health disorders). However, few of the studies on which these recommendations are based included tobacco use treatment interventions for smokers with behavioral health conditions (Fiore et al. 2008; American Psychiatric Association 2016). While evidence is growing on the efficacy of combined behavioral counseling and pharmacotherapy for this population (Banham and Gilbody 2010; Stapleton et al. 2008; Gilbody et al. 2015; Evins et al. 2014), many questions remain understudied, including the evaluation of tobacco use treatment programs in different settings such as community mental health centers and club house programs (Ziedonis et al. 2008; Aubin et al. 2012; Lee et al. 2011; Baker et al. 2016).

The smoking rate for persons without behavioral health conditions has significantly decreased over the past decade, but smoking among persons with behavioral health conditions has declined at a much slower rate (Cook et al. 2014). Persons with behavioral health conditions smoke at roughly twice the rate of those without behavioral health conditions (Lasser et al. 2000; Schroeder and Morris 2010). Smoking rates vary by specific diagnosis, with over $60 \%$ smoking rates for persons with schizophrenia (de Leon and Diaz 
2005) and up to roughly $90 \%$ for those in addiction treatment settings (Guydish et al. 2011).

Adults with behavioral health conditions also smoke at a greater intensity, consuming $44 \%$ of all cigarettes smoked by adults (Lasser et al. 2000) while comprising only $22 \%$ of the nation's population (Ziedonis et al. 2008). Persons with behavioral health conditions are more likely to be nicotine dependent and have lower quit rates than persons without behavioral health conditions (Centers for Disease Control and Prevention 2013; Lasser et al. 2000). However, a systematic review of literature measuring cessation motivation (e.g., stages of change, the contemplation ladder) found that smokers with behavioral health conditions have motivation to quit comparable to the general population; in the majority of included studies, smokers with behavioral health conditions were distributed similarly to the general population within the contemplation stage of smoking cessation (i.e., considering quitting in the next 6 months) and the preparation stage (i.e., planning to quit within the next 30 days) (Siru et al. 2009). The increasing disparity in tobacco use for those with behavioral health conditions suggests that tobacco control interventions have been less effective in this population (Cook et al. 2014). Even population-based strategies, such as mass media campaigns and increased tobacco excise taxes, may be less effective for persons with behavioral health conditions compared to the general population (Ashton et al. 2014; Paul et al. 2013).

Another reason that the behavioral health population experiences some of the largest disparities in tobacco use and tobacco-related health outcomes (Williams et al. 2013) is that tobacco use treatment for persons with behavioral health conditions has been largely ignored. Contributing factors to this problem include continued tolerance of the idea that smoking is normative self-medicating behavior, promotion of harm reduction principles (e.g., tobacco is less harmful and a lower treatment priority compared to illicit drug use), lack of provider training, the historical precedent of allowing or encouraging smoking in behavioral health facilities, and the misconception that cessation will aggravate mental illness symptoms (Hall 2007; Ziedonis et al. 2008; Aubin et al. 2012; Schroeder and Morris 2010; Prochaska 2010; Mackowick et al. 2012). Tobacco use is often not assessed by behavioral health specialists and is rarely included in treatment plans in inpatient settings (Schroeder and Morris 2010), though research indicates tobacco cessation and mental health and substance use treatment can occur concurrently without adverse effects and is even associated with reduced depression, anxiety, and stress (Ziedonis et al. 2008; Schroeder and Morris 2010; Evins et al. 2015; Prochaska et al. 2008; Banham and Gilbody 2010; Taylor 2014).

The relative lack of evaluation of tobacco treatment programs in community settings that serve behavioral health populations limits development of a more robust evidence base. Recent studies report that quitline callers with behavioral health conditions are less likely to quit than callers without behavioral health conditions (Hebert et al. 2011; Kerkvliet et al. 2015; Lukowski et al. 2015; Vickerman et al. 2015). However, few quitline programs tailor services specifically for callers with behavioral health conditions (Rogers and Sherman 2010). In community mental health settings, tailored tobacco use treatment programs are feasible and well received (Lee et al. 2011), but the evaluation of outcomes from such community-based programs is limited (Ziedonis et al. 2008; Ashton et al. 2013). Examining outcomes from tobacco use cessation interventions in real-world settings for smokers with behavioral health conditions provides insight not captured by gold standard controlled trials, as trials often exclude persons with mental illness and/or substance use (Doolan and Froelicher 2006) and results do not necessarily translate seamlessly into community settings (Miller and Shinn 2005). To fill that gap, this study examines outcomes from a state-wide community-based tobacco cessation program among participants based on their behavioral health status. Specifically, we assessed how participants with and without behavioral health conditions compared in regard to program utilization (i.e., number of counseling sessions attended and NRT use) and program outcomes (i.e., 30-day quit at 4-month follow-up). As participants with behavioral health conditions received tailored counseling, we hypothesized similar outcomes would be seen among all participants regardless of behavioral health status.

\section{Methods}

\section{Setting}

Eight community-based tobacco cessation programs in local health and behavioral health clinics were implemented in 2013 as a component of Connecticut's Tobacco Use Prevention and Control Program. These programs were set in various community environments: three programs were located in health departments, two in behavioral health agencies, two in community health centers, and one in a hospital. Programs were contracted by the Connecticut Department of Public Health to target highrisk tobacco users, including those with mental illness and substance use. To recruit participants, staff primarily focused outreach and promotional efforts on providers within and outside their agency and trained providers on tobacco use assessment and referral. 


\section{Intervention}

Participants who enrolled in the program received face-toface counseling from a tobacco treatment specialist in individual and/or group settings, including an intensive oneon-one session at the time of enrollment. All counseling activities were based on the 2008 Clinical Practice Guideline for Treating Tobacco Use and Dependence (Fiore et al. 2008). Group sessions were informed by the American Lung Association's "Freedom from Smoking ${ }^{\circledR}$ ", program (American Lung Association 2016) and when appropriate, tailored to participants with mental illness using the "Learning About Healthy Living" curriculum (Williams et al. 2012) developed specifically for that population. Program completion was defined as completing five individual counseling sessions or eight group sessions; participants were able to receive additional counseling sessions after official program completion as part of e lapse prevention. In addition to counseling, participants were eligible to receive twelve weeks of nicotine replacement therapy (NRT) or other cessation medication (i.e., bupropion or varenicline), as medically appropriate, free of charge.

\section{Sample}

Current smokers (defined as smoking cigarettes within the past 30 days) aged 18 and older who enrolled between 2013 and 2015 and attended at least one counseling session were considered for analysis $(n=1086)$. Participants with complete baseline data were included in the final sample $(\mathrm{n}=974)$.

\section{Measures}

Baseline participant characteristics were self-reported at the time of enrollment, including current smoking status, health history, and previous quit attempts. Program participants were considered to have a current behavioral health condition if they reported currently receiving counseling, treatment, or medication for mental health, emotional, behavioral, or substance use problems (including depression, anxiety, schizophrenia, bipolar disorder, gambling, or alcohol or other drug abuse) at the time of enrollment. Outcomes at 4-month follow-up, such as changes in smoking behavior and use of pharmacotherapy while enrolled in the program, were also self-reported. Cessation was defined as 30-day point prevalence abstinence at 4-month follow-up. Due to low overall follow-up response rates $(31.9 \%)$, both intent-to-treat quit rate analysis (i.e., a conservative analysis that assumes all non-responders continue to smoke), and responder quit rate analysis (i.e., an overestimate of the quit rate that excludes all non-responders from the denominator), were used to estimate program cessation rates.

\section{Data Analysis}

Chi square tests for categorical variables and Wilcoxon-Mann-Whitney tests for nonparametric continuous variables were used to identify differences in participant characteristics and program utilization among those with and without behavioral health conditions. A generalized linear model accounting for clustering of participants at different program sites was used to examine predictors of smoking cessation at 4-month follow-up, adjusting for participant and program utilization characteristics identified $a$ priori based on prior literature and available baseline data (Caponnetto and Polosa 2008), including demographics, smoking intensity, previous quit attempts, cessation medication use, and behavioral health status. The intent-to-treat quit rate was the dependent variable in the model (i.e., nonresponders were assumed to be continuing smokers). Data were analyzed in SAS Version 9.4 (SAS Institute, Inc., Cary, NC).

This study was conducted in accordance with the Declaration of Helsinki, and the protocol was approved by the Institutional Review Board at the University of North Carolina at Chapel Hill (Study \#14-0651). The authors have no conflicts of interest. All authors certify their responsibility for this study and manuscript.

\section{Results}

\section{Sample}

Participants $(n=974)$ were primarily white $(78 \%)$, had lower educational attainment (63\% with high school/GED degree or lower), and had government-sponsored insurance (73\%) (Table 1). Roughly half of participants were heavy smokers (47\% smoked at least 20 cigarettes per day at the time of enrollment), most $(85 \%)$ had made a previous quit attempt, and $65 \%$ reported a current behavioral health condition, such as mental illness or substance use, with $18 \%$ reporting dual diagnosis (i.e., mental health and substance use disorder). Participants with a behavioral health condition were more likely to be younger, non-Hispanic, and have Medicaid insurance.

\section{Program Utilization and Outcomes}

Participants attended an average of nearly five counseling sessions; participants with a behavioral health condition were slightly more likely than participants without a behavioral health condition to complete the programdefined as completing five individual or eight group counseling sessions - though this difference was not significant ( $44.4 \%$ compared to $40.2 \%$, respectively). Nearly half of 
Table 1 Participant characteristics

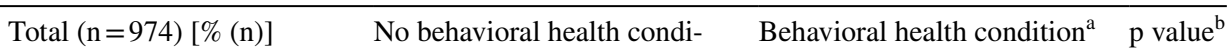
tion $(\mathrm{n}=343)[\%(\mathrm{n})] \quad(\mathrm{n}=631)[\%(\mathrm{n})]$

\begin{tabular}{|c|c|c|c|c|}
\hline \multicolumn{5}{|l|}{ Age } \\
\hline Mean (SD) & $46.0(13.5)$ & $49.2(13.2)$ & $44.3(13.3)$ & $<.0001$ \\
\hline \multicolumn{5}{|l|}{ Gender } \\
\hline Male & $50.6 \%(493)$ & $48.1 \%(165)$ & $52.0 \%(328)$ & \multirow[t]{2}{*}{.25} \\
\hline Female & $49.4 \%(481)$ & $51.9 \%(178)$ & $48.0 \%(303)$ & \\
\hline \multicolumn{5}{|l|}{ Race } \\
\hline White & $77.6 \%(756)$ & $74.9 \%(257)$ & $79.1 \%(499)$ & \multirow[t]{3}{*}{.23} \\
\hline Black & $10.7 \%(104)$ & $12.8 \%(44)$ & $9.5 \%(60)$ & \\
\hline Other & $11.7 \%(114)$ & $12.2 \%(42)$ & $11.4 \%(72)$ & \\
\hline \multicolumn{5}{|l|}{ Ethnicity } \\
\hline Non-Hispanic & $79.3 \%(772)$ & $74.3 \%(255)$ & $81.9 \%(517)$ & \multirow[t]{2}{*}{.005} \\
\hline Hispanic & $20.7 \%(202)$ & $25.7 \%(88)$ & $18.1 \%(114)$ & \\
\hline \multicolumn{5}{|l|}{ Education } \\
\hline$<$ High school & $23.9 \%(233)$ & $26.5 \%(91)$ & $22.5 \%(142)$ & \multirow[t]{3}{*}{.13} \\
\hline High school degree/GED & $39.4 \%(384)$ & $35.3 \%(121)$ & $41.7 \%(263)$ & \\
\hline Some college+ & $36.7 \%(357)$ & $38.2 \%(131)$ & $35.8 \%(226)$ & \\
\hline \multicolumn{5}{|l|}{ Insurance } \\
\hline Private & $20.1 \%(196)$ & $37.3 \%(128)$ & $10.8 \%(68)$ & \multirow[t]{4}{*}{$<.0001$} \\
\hline Medicaid & $58.6 \%(571)$ & $37.6 \%(129)$ & $70.1 \%(442)$ & \\
\hline Medicare & $14.0 \%(136)$ & $12.8 \%(44)$ & $14.6 \%(92)$ & \\
\hline Uninsured & $7.3 \%(71)$ & $12.2 \%(42)$ & $4.6 \%(29)$ & \\
\hline \multicolumn{5}{|l|}{ Cigarettes per day } \\
\hline $0-10$ & $37.0 \%(360)$ & $39.1 \%(134)$ & $35.8 \%(226)$ & \multirow[t]{3}{*}{.31} \\
\hline $11-19$ & $15.7 \%(153)$ & $16.9 \%(58)$ & $15.1 \%(95)$ & \\
\hline $20+$ & $47.3 \%(461)$ & $44.0 \%(151)$ & $49.1 \%(310)$ & \\
\hline \multicolumn{5}{|l|}{ Previous quit attempt } \\
\hline Yes & $85.1 \%(829)$ & $86.9 \%(298)$ & $84.2 \%(531)$ & \multirow[t]{2}{*}{.25} \\
\hline No & $14.9 \%(145)$ & $13.1 \%(45)$ & $15.9 \%(100)$ & \\
\hline \multicolumn{5}{|l|}{ Behavioral health condition } \\
\hline Total & $64.8 \%(631)$ & N/A & $100 \%(631)$ & \multirow[t]{9}{*}{ N/A } \\
\hline Anxiety & $40.6 \%(395)$ & & $62.6 \%(395)$ & \\
\hline Depression & $39.0 \%(380)$ & & $60.2 \%(380)$ & \\
\hline Substance use & $29.7 \%(289)$ & & $54.2 \%(289)$ & \\
\hline Bipolar disorder & $11.8 \%(115)$ & & $18.2 \%(115)$ & \\
\hline Schizophrenia & $4.6 \%(45)$ & & $7.1 \%(45)$ & \\
\hline Gambling & $1.0 \%(10)$ & & $1.6 \%(10)$ & \\
\hline $2+$ behavioral health conditions & $39.0 \%(380)$ & & $60.2 \%(380)$ & \\
\hline $\begin{array}{l}\text { Mental health and substance use } \\
\text { disorder dual diagnosis }\end{array}$ & $18.2 \%(177)$ & & $28.1 \%(177)$ & \\
\hline
\end{tabular}

${ }^{\text {a }}$ Program participants were considered to have a current behavioral health condition if they reported currently receiving counseling, treatment, or medication for mental health, emotional, behavioral, or substance use problems (including depression, anxiety, schizophrenia, bipolar disorder, gambling, or alcohol or other drug abuse) at the time of enrollment

${ }^{\mathrm{b}} \mathrm{p}$ value from Chi square test (categorical variables) and Wilcoxon-Mann-Whitney test (nonparametric continuous variables)

all participants (45\%) used NRT or other cessation medication (i.e., bupropion or varenicline) during the program (Table 2); participants with behavioral health conditions were more likely than participants without behavioral health conditions to have used NRT or other cessation medication (47.5\% compared to $40.2 \%$, respectively; $\mathrm{p}=.03)$.

Response rates at 4-month follow-up were $31.9 \%$. Follow-up respondents were significantly more likely to be female; ages 35 years or older; have Medicare or private 
Table 2 Program utilization and smoking status at 4-month follow-up, by behavioral health status

\begin{tabular}{lcll}
\hline & Total $(\mathrm{n}=974) \%(\mathrm{n})$ & $\begin{array}{l}\text { No behavioral health condition } \\
(\mathrm{n}=343) \%(\mathrm{n})\end{array}$ & $\begin{array}{l}\text { Behavioral health condition }_{(\mathrm{n}=631) \%(\mathrm{n})} \\
\mathrm{p} \text { value }\end{array}$ \\
\hline $\begin{array}{l}\text { Sessions attended } \\
\text { Mean (SD) }\end{array}$ & $4.7(3.5)$ & $4.3(3.1)$ & $4.8(3.7)$ \\
$\begin{array}{l}\text { Program completion } \\
\text { Y }\end{array}$ & $42.6 \%(415)$ & $39.4 \%(135)$ & $44.4 \%(280)$ \\
Yes & & & .13 \\
Used NRT or other cessation medication & $40.2 \%(138)$ & $47.5 \%(300)$ \\
Any cessation medication & $45.0 \%(438)$ & $38.5 \%(132)$ & $43.7 \%(276)$ \\
NRT & $41.9 \%(408)$ & $3.8 \%(13)$ & $5.9 \%(37)$ \\
Varenicline & $5.1 \%(50)$ & $1.8 \%(6)$ & $2.1 \%(13)$ \\
Bupropion & $2.0 \%(19)$ & & .03 \\
30-day quit rate & & $35.0 \%(120)$ & .13 \\
Response rate & $31.9 \%(311)$ & $29.2 \%(35)$ & $30.3 \%(191)$ \\
Responder quit rate & $30.6 \%(95)$ & $10.2 \%(35)$ & $31.4 \%(60)$ \\
Intent-to-treat quit rate & $9.8 \%(95)$ & $9.5 \%(60)$ \\
\hline
\end{tabular}

$N R T$ nicotine replacement therapy

${ }^{a} \mathrm{p}$ value from Chi square test (categorical variables) and Wilcoxon-Mann-Whitney test (nonparametric continuous variables)

${ }^{\mathrm{b}}$ Program completion is defined as completing five individual counseling sessions or eight group counseling sessions

insurance; have tried to quit tobacco previously; have used cessation medication during the program; and have completed the program. Response rates did not significantly differ by behavioral health status, though follow-up respondents were less likely to have a substance use and mental health disorder dual diagnosis. As intent-to-treat analysis was used in the generalized linear model, participants who did not respond to follow-up were assumed to still be using tobacco. Thus, results should be interpreted with caution, as certain groups had significantly lower response rates. Intent-to-treat quit rates were $9.8 \%$ and responder quit rates were $30.6 \%$.

Accounting for clustering of participants at multiple program sites, a generalized linear model was used to examine the adjusted effects of participant demographics, smoking characteristics, behavioral health status, and program utilization on 30-day quit status at 4-month follow-up, using intent-to-treat analysis (Table 3). No demographic factors were associated with being quit. The likelihood of being quit increased for participants who had previously made a quit attempt $(\mathrm{AOR}=2.09,95 \%$ CI $1.13,3.87 ; \mathrm{p}=.02$ ), who used NRT or other cessation medication during the program $(\mathrm{AOR}=3.03,95 \% \mathrm{CI}$ $1.42,6.45 ; \mathrm{p}=.004)$, and who attended more counseling sessions $(\mathrm{AOR}=1.15,95 \%$ CI 1.08, 1.21; $\mathrm{p}<.0001)$. Heavier smokers (i.e., smoking at least 20 cigarettes per day at time of enrollment) had lower likelihood of being quit $(\mathrm{AOR}=0.62,95 \%$ CI $0.38,0.99 ; \mathrm{p}=.05)$. No significant differences were observed in the likelihood of being quit between those with and without a reported behavioral health condition or between those with and without a mental health and substance use disorder dual diagnosis.

\section{Discussion}

This study provides evaluation of smoking cessation treatment in real world, community-based settings for smokers across a state, with and without behavioral health conditions. Our findings suggest that evidence-based tobacco use treatment for smokers with behavioral health conditions can be successfully implemented in a variety of community-based health and behavioral health settings. Participants with behavioral health conditions in these programs were successfully recruited and treated; roughly $65 \%$ of the participants enrolled in the programs reported a current behavioral health condition, and these participants achieved comparable program completion rates and cessation rates to participants without behavioral health conditions. These results add to the limited literature examining predictors of smoking cessation in community-based treatment programs. Importantly, findings show that the likelihood of cessation increased with attending more counseling sessions and using NRT or other cessation medication during the program, with no differences in quit rates between participants with and without behavioral health conditions or between participants with and without a mental health and substance use disorder dual diagnosis. 
Table 3 Predictors of smoking abstinence $(n=974)$

\begin{tabular}{|c|c|c|}
\hline & $\operatorname{AOR}(95 \% \mathrm{CI})^{\mathrm{a}}$ & $\mathrm{p}$ value \\
\hline Age & $1.02(1.0,1.05)$ & .06 \\
\hline \multicolumn{3}{|l|}{ Gender } \\
\hline Male & Ref & - \\
\hline Female & $0.88(0.54,1.43)$ & .60 \\
\hline \multicolumn{3}{|l|}{ Race } \\
\hline White & Ref & - \\
\hline Black & $1.08(0.56,2.07)$ & .83 \\
\hline Other & $1.25(0.39,4.03)$ & .71 \\
\hline \multicolumn{3}{|l|}{ Ethnicity } \\
\hline Non-Hispanic & 0 & - \\
\hline Hispanic & $0.97(0.25,3.69)$ & .96 \\
\hline \multicolumn{3}{|l|}{ Education } \\
\hline Some college+ & Ref & - \\
\hline High school degree/GED & $0.60(0.31,1.18)$ & .14 \\
\hline$<$ High school & $1.06(0.53,2.13)$ & .87 \\
\hline \multicolumn{3}{|l|}{ Insurance } \\
\hline Private & Ref & - \\
\hline Medicaid & $1.31(0.67,2.56)$ & .43 \\
\hline Medicare & $1.73(0.72,4.16)$ & .22 \\
\hline Uninsured & $0.73(0.44,1.22)$ & .24 \\
\hline \multicolumn{3}{|l|}{ Cigarettes per day } \\
\hline $0-10$ & Ref & - \\
\hline $11-19$ & $0.77(0.30,1.98)$ & .59 \\
\hline $20+$ & $0.62(0.38,0.99)$ & .05 \\
\hline \multicolumn{3}{|l|}{ Previous quit attempt } \\
\hline No & Ref & - \\
\hline Yes & $2.09(1.13,3.87)$ & .02 \\
\hline \multicolumn{3}{|c|}{ Used NRT or other cessation medication } \\
\hline No & Ref & - \\
\hline Yes & $3.03(1.42,6.45)$ & .004 \\
\hline Sessions attended & $1.15(1.08,1.21)$ & $<.0001$ \\
\hline \multicolumn{3}{|l|}{ Behavioral health condition } \\
\hline No & Ref & - \\
\hline Yes & $0.81(0.47,1.38)$ & .43 \\
\hline \multicolumn{3}{|c|}{ Mental health and substance use disorder dual diagnosis } \\
\hline No & Ref & - \\
\hline Yes & $0.73(0.39,1.37)$ & .32 \\
\hline
\end{tabular}

Self-reported 30-day point prevalence abstinence at 4-month followup using intent-to-treat analysis

AOR adjusted odds ratio, $C I$ confidence interval

${ }^{a}$ Adjusted odds ratio from a generalized linear model accounting for clustering of program participants at eight different program sites and adjusted for all listed variables

These findings support tobacco use treatment guidelines recommending combined counseling and pharmacotherapy for tobacco users with behavioral health conditions (Fiore et al. 2008). Results are also consistent with prior studies and contribute to growing evidence that treatment can be implemented successfully in settings such as community mental health centers. For instance, another communitybased smoking cessation program found that smokers with mental illness who received behavioral counseling and NRT achieved quit rates comparable to smokers without mental illness, with no negative impact on mental health symptoms (Currie et al. 2008). Further, relapse prevention conducted in community mental health centers using combined cognitive behavioral therapy and varenicline improved prolonged abstinence rates compared with cognitive behavioral therapy alone (Evins et al. 2014). Increasing efforts are being made to develop and evaluate cessation programs specifically for people with mental illness, such as the Smoking Cessation Intervention for Severe Mental Ill Health Trial, providing tailored behavioral support and pharmacotherapy delivered by mental health nurses (Gilbody et al. 2015).

Systems-level changes within health and behavioral health settings, such as integrating tobacco use assessment into providers' intake processes (McCullough et al. 2009), training providers on tobacco use treatment, and implementing smoke and tobacco-free policies on facility grounds, can help de-normalize smoking among persons with behavioral health conditions and staff members and encourage the use of evidence-based support. Perceived lack of patient interest in quitting and a high demand on clinician time and attention are cited as primary barriers to delivering tobacco use treatment in community behavioral health centers (Brown et al. 2015). However, a single motivational session can encourage tobacco users with behavioral health conditions to utilize cessation counseling and/ or pharmacotherapy (Ferron et al. 2016), which in turn can lead to a higher likelihood of quitting. Increasing discussion between providers and patients with behavioral health conditions about evidence-based cessation treatment and improving accessibility to such treatment should be a priority.

\section{Limitations}

As this evaluation study was naturalistic and utilized data from community-based programs that were not designed or implemented as part of a formal research study, several limitations exist. To account for potential selection bias resulting from a low response rate at follow-up (31.9\%), we used intent-to-treat analysis, assuming non-responders were continuing smokers. Future programs should consider offering a small incentive to participants or conduct shorter term follow up (e.g., 1 and 3 months post program enrollment) to facilitate higher follow-up response rates. The possibility of reverse causation must be considered in regard to program utilization (i.e., counseling sessions and pharmacotherapy) as a significant predictor of quit, such that participants who made positive changes to their smoking behavior early in 
the program (e.g., tapering, abstaining) were more likely to stay engaged and use available NRT or other cessation medication and complete more sessions than participants experiencing an early set-back that may have led to dropout. Finally, conclusions are limited by self-reported data. Smoking abstinence was not biologically verified, though self-reported smoking status can be valid and is often the only method many community-based programs can afford to collect data on program outcomes (Wong et al. 2012). Behavioral health conditions were defined broadly with no indication of condition severity, rather than by specific $D S M$ diagnoses, limiting our ability to offer recommendations based upon specific clinical diagnoses in terms of most successful treatment protocol and barriers to quitting. For instance, participants with more severe diagnoses may have been more likely to discontinue the program or may have been less likely to quit, as has been observed in other studies (Cook et al. 2014). Despite these limitations, quit rates in this evaluation appear similar to published quit rates from other comparable community-based cessation programs for smokers with behavioral health conditions (Ashton et al. 2013; Currie et al. 2008).

\section{Conclusions}

This study addresses a significant challenge of enhancing the impact of smoking cessation interventions for those with behavioral health conditions, a largely underserved group. Findings add to the limited literature evaluating community-based interventions, particularly within the behavioral health population. Importantly, community programs in local health and behavioral health agencies were able to reach a high proportion of smokers with behavioral health conditions and these participants achieved comparable quit success to participants without behavioral health conditions. Health professionals should encourage tobacco users with behavioral health conditions to participate in community cessation programs and behavioral health agencies should consider integrating tobacco use treatment programs into their services.

Funding This work was supported by the Connecticut Department of Public Health Tobacco Cessation Program Evaluation contract. Any opinions, findings, conclusions, or recommendations expressed in this publication are those of the authors and do not necessarily reflect the views and policies of the Connecticut Department of Public Health.

\section{References}

American Lung Association. (2016). Freedom from Smoking. Retrieved May 3, 2016 from http://www.lung.org/stop-smoking/ how-to-quit/freedom-from-smoking/.
American Psychiatric Association. (2016). Practice guideline for the treatment of patients with substance use disorders, second edition. American Journal of Psychiatry, 163(8), 1-275.

Ashton, M., Rigby, A., \& Galletly, C. (2013). Evaluation of a community-based smoking cessation programme for people with severe mental illness. Tobacco Control, 275-280.

Ashton, M., Rigby, A., \& Galletly, C. (2014). Do population-wide tobacco control approaches help smokers with mental illness? The Australian and New Zealand Journal of Psychiatry, 48(2), 121-123.

Aubin, H.-J., Rollema, H., Svensson, T. H., \& Winterer, G. (2012). Smoking, quitting, and psychiatric disease: A review. Neuroscience and Biobehavioral Reviews, 36(1), 271-284.

Baker, H. M., Ranney, L. M., \& Goldstein, A. O. (2016). Pilot implementation of a wellness and tobacco cessation curriculum in North Carolina group homes. Community Mental Health Journal, 52(4), 433-438.

Banham, L., \& Gilbody, S. (2010). Smoking cessation in severe mental illness: What works? Addiction, 105(7), 1176-1189.

Brown, C. H., Medoff, D., Dickerson, F. B., Fang, L. J., Lucksted, A., Goldberg, R. W., et al. (2015). Factors influencing implementation of smoking cessation treatment within community mental health centers. Journal of Dual Diagnosis, 11(2), 145-150.

Caponnetto, P., \& Polosa, R. (2008). Common predictors of smoking cessation in clinical practice. Respiratory Medicine, 102(8), 1182-1192.

Centers for Disease, C., \& Prevention. (2011). Quitting smoking among adults-United States, 2001-2010. MMWR Morbidity and Mortality Weekly Report, 60(44), 1513-1519.

Centers for Disease, C., \& Prevention. (2013). Vital signs: Current cigarette smoking among adults aged $\geq 18$ years with mental illness: United States, 2009-2011. MMWR Morbidity and Mortality Weekly Report, 62(5), 81-87.

Cook, B. L., Wayne, G. F., Kafali, E. N., Liu, Z., Shu, C., \& Flores, M. (2014). Trends in smoking among adults with mental illness and association between mental health treatment and smoking cessation. Journal of the American Medical Association, 311(2), 172-182.

Currie, S. R., Karltyn, J., Lussier, D., de Denus, E., Brown, D., \& ElGuebaly, N. (2008). Outcome from a community-based smoking cessation program for persons with serious mental illness. Community Mental Health Journal, 44(3), 187-194.

de Leon, J., \& Diaz, F. J. (2005). A meta-analysis of worldwide studies demonstrates an association between schizophrenia and tobacco smoking behaviors. Schizophrenia Research, 76(2-3), 135-157.

Doolan, D. M., \& Froelicher, E. S. (2006). Efficacy of smoking cessation intervention among special populations: review of the literature from 2000 to 2005. Nursing Research, 55(4 Suppl), S29-S37.

Evins, A. E., Cather, C., \& Laffer, A. (2015). Treatment of tobacco use disorders in smokers with serious mental illness: toward clinical best practices. Harvard Review of Psychiatry, 23(2), 90-98.

Evins, A. E., Cather, C., Pratt, S. A., Pachas, G. N., Hoeppner, S. S., Goff, D. C., et al. (2014). Maintenance treatment with varenicline for smoking cessation in patients with schizophrenia and bipolar disorder: A randomized clinical trial. Journal of the American Medical Association, 311(2), 145-154.

Ferron, J. C., Devitt, T., McHugo, G. J., Jonikas, J. A., Cook, J. A., \& Brunette, M. F. (2016). Abstinence and use of community-based cessation treatment after a motivational intervention among smokers with severe mental illness. Community Mental Health Journal, 52(4), 446-456.

Fiore, M. C., Jaén, C., Baker, T. B., et al. (2008). Clinical practice guideline: Treating tobacco use and dependence: 2008 update. Retrieved from http://www.ahrq.gov/professionals/ 
clinicians-providers/guidelines-recommendations/tobacco/clinicians/update/treating_tobacco_use08.pdf.

Gilbody, S., Peckham, E., Man, M. S., Mitchell, N., Li, J. S., Becque, T., et al. (2015). Bespoke smoking cessation for people with severe mental ill health (SCIMITAR): a pilot randomised controlled trial. Lancet Psychiatry, 2(5), 395-402.

Guydish, J., Passalacqua, E., Tajima, B., Chan, M., Chun, J., \& Bostrom, A. (2011). Smoking prevalence in addiction treatment: A review. Nicotine \& Tobacco Research, 13(6), 401-411.

Hall, S. M. (2007). Nicotine interventions with comorbid populations. American Journal of Preventive Medicine, 33(6 Suppl), S406-S413.

Hebert, K. K., Cummins, S. E., Hernandez, S., Tedeschi, G. J., \& Zhu, S.-H. (2011). Current major depression among smokers using a state quitline. American Journal of Preventive Medicine, 40(1), 47-53.

Jamal, A., Agaku, I. T., O’Connor, E., King, B. A., Kenemer, J. B., \& Neff, L. (2014). Current cigarette smoking among adults: United States, 2005-2013. MMWR Morbidity and Mortality Weekly Report, 63(47), 1108-1112.

Kerkvliet, J. L., Wey, H., \& Fahrenwald, N. L. (2015). Cessation among state quitline participants with a mental health condition. Nicotine \& Tobacco Research, 17(6), 735-741.

Lasser, K. E., Boyd, J. W., Woolhandler, S. J., Himmelstein, D. U., McCormick, D., \& Bor, D. H. (2000). Smoking and mental illness: A population-based prevalence study. Journal of General Internal Medicine, 15, 79-79.

Lee, J. G. L., Ranney, L. M., Goldstein, A. O., McCullough, A., Fulton-Smith, S. M., \& Collins, N. O. (2011). Successful implementation of a wellness and tobacco cessation curriculum in psychosocial rehabilitation clubhouses. BMC Public Health, 11, 702.

Lukowski, A. V., Morris, C. D., Young, S. E., \& Tinkelman, D. (2015). Quitline outcomes for smokers in 6 states: rates of successful quitting vary by mental health status. Nicotine \& Tobacco Research, 17(8), 924-930.

Mackowick, K. M., Lynch, M.-J., Weinberger, A. H., \& George, T. P. (2012). Treatment of tobacco dependence in people with mental health and addictive disorders. Current Psychiatry Reports, 14(5), 478-485.

McCullough, A., Fisher, M., Goldstein, A. O., Kramer, K. D., \& Ripley-Moffitt, C. (2009). Smoking as a vital sign: prompts to ask and assess increase cessation counseling. The Journal of the American Board of Family Medicine, 22(6), 625-632.

Miller, R. L., \& Shinn, M. (2005). Learning from communities: Overcoming difficulties in dissemination of prevention and promotion efforts. American Journal of Community Psychology, 35(3-4), $169-183$.

Paul, C. L., Turon, H., Bonevski, B., Bryant, J., \& McElduff, P. (2013). A cross-sectional survey of experts' opinions about the relative effectiveness of tobacco control strategies for the general population versus disadvantaged groups: what do we choose in the absence of evidence? BMC Public Health, 13, 1144.
Prochaska, J. J. (2010). Failure to treat tobacco use in mental health and addiction treatment settings: A form of harm reduction? Drug and Alcohol Dependence, 110(3), 177-182.

Prochaska, J. J., Hall, S. M., Tsoh, J. Y., Eisendrath, S., Rossi, J. S., Redding, C. A., et al. (2008). Treating tobacco dependence in clinically depressed smokers: Effect of smoking cessation on mental health functioning. American Journal of Public Health, 98(3), 446-448.

Rogers, E., \& Sherman, S. E. (2010). State smoking cessation quitlines and smokers with mental illness. Journal of Smoking Cessation, 5(02), 158-163.

Schroeder, S. A., \& Morris, C. D. (2010). Confronting a neglected epidemic: Tobacco cessation for persons with mental illnesses and substance abuse problems. Annual Review of Public Health, 31, 297-314.

Siru, R., Hulse, G. K., \& Tait, R. J. (2009). Assessing motivation to quit smoking in people with mental illness: A review. Addiction, 104(5), 719-733.

Stapleton, J. A., Watson, L., Spirling, L. I., Smith, R., Milbrandt, A., Ratcliffe, M., et al. (2008). Varenicline in the routine treatment of tobacco dependence: A pre-post comparison with nicotine replacement therapy and an evaluation in those with mental illness. Addiction, 103(1), 146-154.

Stead, L. F., \& Lancaster, T. (2012). Combined pharmacotherapy and behavioural interventions for smoking cessation. Cochrane Database of Systematic Reviews. doi:10.1002/14651858.CD008286. pub2.

Taylor, G. (2014). Change in mental health after smoking cessation: Systematic review and meta-analysis. British Medical Journal, $348, \mathrm{~g} 1151$.

Vickerman, K. A., Schauer, G. L., Malarcher, A. M., Zhang, L., Mowery, P., \& Nash, C. M. (2015). Quitline use and outcomes among callers with and without mental health conditions: A 7-month follow-up evaluation in three states. BioMed Research International, 2015, 817298.

Williams, J. M., Steinberg, M. L., Griffiths, K. G., \& Cooperman, N. (2013). Smokers with behavioral health comorbidity should be designated a tobacco use disparity group. American Journal of Public Health, 103(9), 1549-1555.

Williams, J. M., Ziedonis, D., Speelman, N., Vreeland, B., Zechner, M., Rahim, R., O'Hea, E. (2012). Learning about Healthy Living: Tobacco and You Manual: RWJMS Division of Addiction Psychiatry.

Wong, S. L., Shields, M., Leatherdale, S., Malaison, E., \& Hammond, D. (2012). Assessment of validity of self-reported smoking status. Health Reports, 23(1), 47-53.

Ziedonis, D., Hitsman, B., Beckham, J. C., Zvolensky, M., Adler, L. E., Audrain-McGovern, J., et al. (2008). Tobacco use and cessation in psychiatric disorders: National Institute of Mental Health report. Nicotine \& Tobacco Research, 10(12), 1691-1715. 